\title{
Perforación gástrica por espina de pescado. Reporte de un caso y revisión de literatura
}

\section{Gastric perforation caused by fish bone. Case report and literature review}

Yolima Alfaro, ${ }^{1}$ Luis Fernando Rodríguez, ${ }^{2}$ Luis Fernando Molineros, ${ }^{3}{ }^{*}$ Sandra Cifuentes, ${ }^{4}$ Juan Oswaldo Berdugo ${ }^{5}$

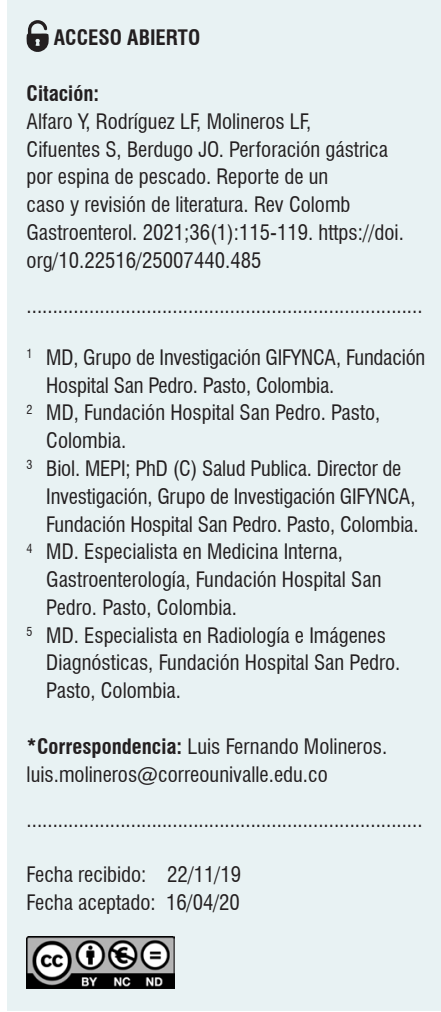

\begin{abstract}
Resumen
La ingesta de cuerpos extraños es una entidad clínica común en el servicio de gastroenterología; la mayoría de veces estos pasan a través del tracto digestivo de manera espontánea y, en algunos casos, pueden presentar complicaciones como obstrucción o perforación. Es importante realizar un diagnóstico temprano con el fin de definir una terapia conservadora o quirúrgica inmediata. Se presenta el caso de una paciente de 67 años de edad que ingresó al servicio de urgencias por dolor abdominal de 16 días de evolución; como había sospecha de tumor gástrico sobreinfectado, se solicitó una endoscopia digestiva alta para la toma de biopsias, pero de forma sorpresiva se extrajo una espina de pescado de $3,5 \mathrm{~cm}$ sin complicaciones; posteriormente, se realizó el manejo del absceso gástrico con antibióticos por 14 días, con un buen desenlace clínico.
\end{abstract}

\section{Palabras clave}

Perforación, gastroscopia, espina de pescado, informe.

\section{Abstract}

Foreign body ingestion is a common reason for consultation to the Gastroenterology Service. Most of these bodies pass through the digestive tract spontaneously and, in some cases, may cause complications such as obstruction or perforation. Early diagnosis is crucial to establish immediate conservative or surgical therapy. The following is the case of a 67-year-old patient admitted to the Emergency Department due to abdominal pain of 16 days of evolution. Since an over-infected gastric tumor was suspected, an upper gastrointestinal endoscopy was requested for biopsy. Strikingly, a $3.5 \mathrm{~cm}$ fish bone was removed without complications. Gastric abscess was treated subsequently with antibiotics for 14 days, obtaining a good clinical outcome.

\section{Keywords}

Perforation, Gastroscopy, Fish bone, Report.

\section{INTRODUCCIÓN}

En gastroenterología, una de las causas de consulta es la ingesta de cuerpo extraño y la más frecuente es la de espina de pescado; aquellas espinas que son largas y puntiagudas pueden causar complicaciones en un $1 \%$ a un $5 \%$, por lo que requieren la extracción por vía endoscópica y, en algunos casos, quirúrgica (1). La perforación del tracto gastrointestinal por espina de pescado ocurre en menos del $1 \%$ de los casos. La tasa de mortalidad es desconocida, 
pero han sido raramente reportadas (2-5). Entre los adultos, la incidencia es mayor cuando se trata de personas con retraso mental o con alteraciones psiquiátricas.

La mala dentición o una inadecuada masticación de los alimentos constituyen claros factores de riesgo. Las prótesis dentarias no consiguen suplir la dentadura propia, lo que compromete la sensibilidad táctil discriminativa de la cavidad bucal. La mala visión se convierte en otro factor añadido que, a menudo, coexiste en estas personas (3). Aproximadamente, el $50 \%$ de las ingestas se queda localizado en el esófago y cerca del $26 \%$ en el estómago; una vez que pasan al estómago, suelen ser expulsadas espontáneamente; un porcentaje bajo queda enclavado en la mucosa gastrointestinal, por ser afilado o de gran tamaño. La región prepilórica y la válvula ileocecal son las dos localizaciones donde se enclavan con mayor frecuencia, por ser zonas de mayor estenosis fisiológica (4).

Es frecuente que el diagnóstico de perforación intestinal por espina de pescado se confunda con algunas de las enfermedades más comunes, como la apendicitis aguda o la diverticulitis aguda, y que no se haga la asociación causal por el tiempo que normalmente transcurre desde la ingestión hasta la aparición de los síntomas, que suelen ser inespecíficos y relacionados con fiebre, malestar y dolor abdominal, que progresa a una peritonitis localizada (5). La endoscopia es un medio de diagnóstico y tratamiento rápido que disminuye la morbilidad. La extracción de los cuerpos extraños mediante endoscopia permite identificar el objeto, valorar el estado de la mucosa subyacente y comprobar si se ha producido alguna complicación (5).

En la perforación intestinal por espina de pescado se pueden presentar básicamente dos posibilidades: una es que la perforación puede localizarse y, mediante los mecanismos de defensa peritoneal, llevar a la formación de plastrón; la otra es que se presente peritonitis secundaria a la perforación. Los gérmenes encontrados con frecuencia son Escherichia coli, Streptococcus, Enterobacter spp., Klebsiella spp., Enterococcus spp., Pseudomonas aeruginosa, Proteus spp., Staphylococcus aureus y Staphylococcus epidermidis. El tratamiento antibiótico debe iniciarse desde antes de la cirugía o del procedimiento endoscópico, continuarse y modificarse de acuerdo con los resultados de los cultivos y evolución clínica (5).

Se presenta un caso en el que la ingesta de espina de pescado produjo una perforación y un absceso gástrico que se resolvió satisfactoriamente de forma endoscópica y con manejo antibiótico.

\section{PRESENTACIÓN DEL CASO CLÍNICO}

Se trata de una paciente femenina de 67 años de edad, sin antecedentes patológicos, quien ingresó al servicio de urgencias con un cuadro clínico de aproximadamente 16 días de evolución de dolor abdominal en el cuadrante superior izquierdo, escalofrío, inapetencia y pérdida de peso de aproximadamente 6 kilos. Dentro de los estudios practicados, inicialmente se tomó una endoscopia digestiva alta, en la que se evidenció una lesión en la vertiente extrínseca de curvatura mayor, con sospecha de lesión subepitelial frente a la compresión extrínseca de $5 \mathrm{~cm}$, con mucosa adyacente normal, ecografía de abdomen, imágenes de engrosamiento de la cama gástrica con imágenes ecogénicas que invaden la luz y sombra acústica posterior, colonoscopia con reporte de diverticulosis y sospecha de tumor sobreinfectado, por lo cual se realizó una tomografía axial computarizada (TAC) de abdomen y se encontró una masa exofitica con densidad de tejidos blandos que se localiza en relación con la curvatura mayor del estómago, aparentemente sólida. Las posibilidades diagnósticas a considerar son tumores del estroma gastrointestinal (GIST gástrico) frente a la reacción al cuerpo extraño (Figura 1). Los marcadores tumorales fueron negativos; el hemograma resultó sin leucocitosis, sin anemia y con PCR elevada $(172,9)$.

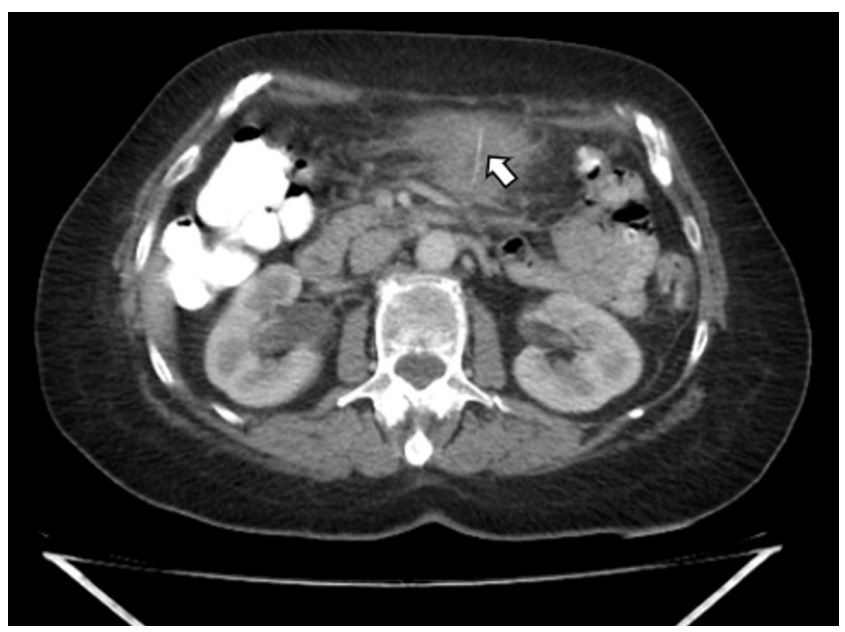

Figura 1. TAC de abdomen contrastado.

Se realizó una segunda endoscopia digestiva alta para definir la localización de la masa y la toma de biopsias; se observó un engrosamiento grave de la mucosa de curvatura mayor con gran eritema. Se tomaron múltiples biopsias y, de forma sorpresiva, se extrajo una espina de pescado de $3,5 \mathrm{~cm}$ (Figuras 2 y 3 ). Posteriormente, se inició el manejo antibiótico para absceso gástrico; se interrogó nuevamente a la paciente, quien negó el consumo de pescado en el último mes o meses previos; se realizó un seguimiento con una TAC abdominal, en la que se evidenció una disminución del tamaño de la lesión y escaso líquido que no amerita drenaje (Figura 4). Se completó el tratamiento antibiótico 
y se realizó una ecografía de abdomen de control con el absceso resuelto.

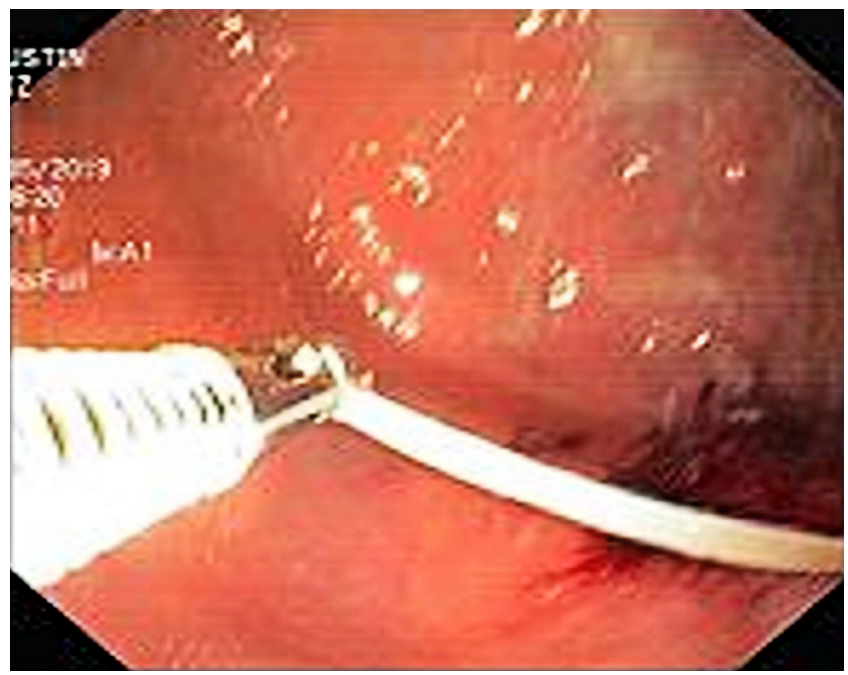

Figura 2. Endoscopia digestiva alta.

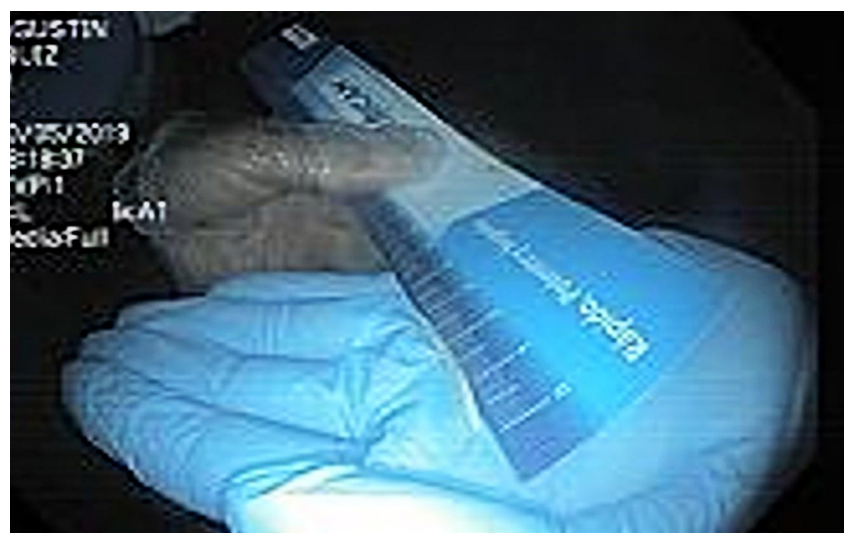

Figura 3. Extracción del hueso de pescado por endoscopia.

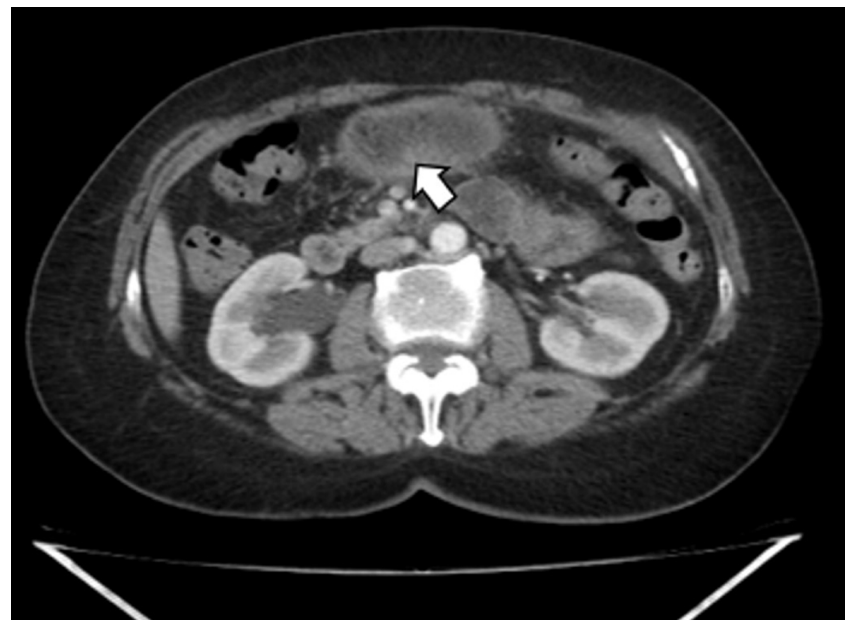

Figura 4. TAC de abdomen contrastado de control.

\section{DISCUSIÓN}

La ingestión de cuerpo extraño es motivo de consulta frecuente en los servicios de urgencias, y la segunda indicación más habitual para la realización de endoscopia digestiva alta urgente (4-9). Se considera que del $80 \%$ al $90 \%$ de los cuerpos extraños pueden pasar de manera espontánea, sin causar daño (3), y solo el $1 \%$ puede generar abscesos o perforaciones, de los cuales los huesos de pescado son la principal causa (2-5). A diferencia de la población pediátrica que ingiere monedas, botones, pilas y objetos de plástico, en los adultos son más frecuentes los objetos orgánicos como bolos de alimentos, espinas de pescado y huesos (6-10); esto se debe a que la gran mayoría de adultos utiliza prótesis dentales, alterando la sensibilidad táctil discriminativa de la cavidad bucal y, además, la mala visión aumenta el riesgo de ingesta involuntaria de un cuerpo extraño (3).

El mayor porcentaje de perforación gastrointestinal por espina de pescado se presenta en el esófago, en aproximadamente un $50 \%$ de las personas; a pesar de ello, la perforación aórtica es una complicación infrecuente. Benítez (11) reportó dos casos con perforación aórtica cuya complicación fue la fistula aortoesofágica con desenlace fatal, lo cual llega al $22 \%$; por esto es importante un diagnóstico oportuno en el que se identifique la localización de la lesión, lo cual contribuye a mejorar el pronóstico vital del paciente. Solo un $26 \%$ de los cuerpos extraños queda enclavado en la mucosa gástrica; y con mayor frecuencia pueden derivar en complicaciones como abscesos, perforación y fistulas $(4,6$, $7,10)$. En niños, es muy común que los cuerpos extraños se localicen a nivel de vía aérea; de acuerdo con la ubicación del cuerpo extraño, se presentan los síntomas que pueden ir desde tos hasta dificultad respiratoria. En estos casos se justifica la realización de broncoscopia, por tratarse de un procedimiento diagnóstico y terapéutico, y que a la vez es seguro, por lo que se convierte en el estándar de oro para remover cuerpos extraños en niños; y su retraso podría aumentar el riesgo de complicaciones (12-14).

Un diagnóstico rápido y oportuno disminuye la morbimortalidad; en algunos casos, se puede presentar con síntomas atípicos e inespecíficos que enmascaran la lesión y más cuando no se tiene un antecedente claro de ingesta de cuerpo extraño. La sintomatología en este caso fue poco específica y se desconocía el antecedente de ingesta de pescado, lo que generó un diagnóstico erróneo; el tiempo de presentación de los síntomas no fue inmediato, dado que la paciente llevaba aproximadamente 16 días con sintomatología, pero se desconocía el tiempo transcurrido entre el consumo de pescado y los síntomas presentados. Garrido (1) reportó un caso similar sobre perforación gástrica por cuerpo extraño de larga permanencia en un paciente que debutó con sintomatología de abdomen agudo cuyo 
cuerpo extraño permaneció aproximadamente por 14 años y que posteriormente necesitó manejo quirúrgico. En el primer caso reportado por Benítez (11), la sintomatología la presentó 12 días después de la ingesta accidental de la espina de pescado.

En todo paciente con sospecha de cuerpo extraño es indispensable la utilización de ayudas diagnósticas; la radiografía simple es útil cuando es radiopaco y para visualizar signos de perforación, como el aire libre en el diafragma, el mediastino, el retroperitoneo o en áreas subcutáneas cervicales (15). La radiografía simple es poco útil, debido a que las espinas de pescado no son radiopacas, además del enmascaramiento por los tejidos blandos y el edema que se produce alrededor del cuerpo extraño. La TAC, además de identificar cuerpos no radiopacos, es de gran utilidad para localizar el segmento y permitir la visualización del cuerpo extraño; por su alta sensibilidad (100\%) y especificidad $(93,7 \%)$ se recomienda como el examen inicial $(8,11,16)$.

Se considera que la existencia de una perforación es una contraindicación absoluta para realizar exploraciones endoscópicas, tanto altas como bajas. Al tratarse de un procedimiento desafiante y de alto riesgo, sobre todo cuando son objetos afilados que pueden causar perforación y sangrado; otro factor de riesgo es la falta de ayuno, que puede generar complicaciones como la broncoaspiración, lo que complica el estado del paciente (12); sin embargo, el tratamiento conservador de las perforaciones pequeñas está bien documentado, siempre y cuando no haya perforaciones abiertas o peritonitis. Con el paso del tiempo se han perfeccionado las técnicas endoscópicas y, en este sentido, cobra importancia, ya que no solo permiten hacer el diagnóstico, sino también la extracción. Por lo general, el manejo clásico ha sido quirúrgico, que se asocia con muy alta morbimortalidad ( $55 \%$ a $78 \%$ ). Cada vez se han publicado más casos en los que se ha utilizado la endoscopia, por ser menos agresiva y con una gran capacidad de resolución (4, 9-11, 15-18). Según Rosón y colaboradores (4), hay reportes de varios casos de perforaciones tanto esofágicas como gástricas y ocasionalmente en el colon, que fueron manejadas de forma adecuada con tratamiento conservador. Es importante el cubrimiento antibiótico que deben recibir los pacientes y, más aún, cuando se generan abscesos. En este caso, el paciente recibió cubrimiento para gérmenes grampositivos y gramnegativos por 14 días, con una respuesta clínica adecuada (5).

Finalmente, en la ingesta de hueso de pescado es frecuente el manejo conservador mediante la extracción por endoscopia, dado que es la alternativa con menor riesgo de morbimortalidad. En el caso de abscesos y peritonitis, es necesario establecer un esquema de tratamiento con antibióticos.

\section{Fuentes de financiación}

Ninguna financiación privada ha sustentado este estudio.

\section{Conflictos de interés}

Los autores declaran no tener ningún conflicto de intereses.

\section{REFERENCIAS}

1. Garrido R, Verástegui T, Huanqui J, Cárdenas B. Abdomen agudo debido a perforación gástrica por cuerpo extraño de larga permanencia. Rev Gastroenterol Perú. 2012;32(1):84-7.

2. Mutlu A, Uysal E, Ulusoy L, Duran C, Selamoğlu D. A fish bone causing ileal perforation in the terminal ileum. Ulus Travma Acil Cerrahi Derg. 2012;18(1):89-91. https://doi. org/10.5505/tjtes.2011.90912

3. Pfau PR, Ginsberg GG. Cuerpos extraños y bezoares. En: Feldman M, Friedman LS, Brandt LJ, eds. Sleisenger y Fordtran. Enfermedades Digestivas y Hepáticas, Fisiopatología, Diagnóstico y Tratamiento, $8^{\text {a }}$ ed. Madrid: Elsevier, 2008:499-513

4. Rosón Rodríguez P, López Ortega S, Melgarejo F, Vásquez Pedreño L, Fernández Castañer A. Seguridad del tratamiento conservador de la perforación gástrica por espina de pescado. Gastroenterol Hepatol. 2009;32(8):552-6. https://doi.org/10.1016/j.gastrohep.2009.04.010
5. Barragán C, Rueda J, Espitia E, Uriza L, Rosselli D. Perforación intestinal por espina de pescado, revisión de la literatura científica y presentación de dos casos. Rev Colomb Cir. 2012;27:79-84.

6. Vásquez M, Rosendo Y, Rodulfo J, Camacaro O. Absceso retrofaríngeo por perforación esofágica con espina de pescado, a propósito de un caso. GEN. 2012;66(2):120-3.

7. Vásquez JC, Montesinos E, Castillo L, Rojas L, Peralta J. Perforación Esofágica y Mediastinitis causada por Espina de Pescado: Reporte de 3 casos. Rev Gastroenterol Perú. 2006;26(4):400-3.

8. Cañete-Celestino E, Gómez P, Núñez-Delgado Y, LópezMartín G, García-Galera A. Perforación gástrica contenida secundaria a peculiar cuerpo extraño. Rapd Online. 2015;38(4):183-5.

9. Ríos G, Alliende F, Miquel I, Arancibia ME, Rodríguez L, Saelzer E. Extracción endoscópica de cuerpos extraños 
digestivos. Rev Chil Ped. 2013;84(5):505-512. http:// dx.doi.org/10.4067/S0370-41062013000500004

10. Núñez Ó, Sanz C, Pérez I, Holguera L, Alberdi J. Resolución endoscópica de perforación gástrica con penetración a páncreas por espina de pescado. Gastroenterol Hepatol. 2018;41(9):567-8. https://doi.org/10.1016/j. gastrohep.2017.11.002

11. Benítez E, Alfonso M, Lesmes MC, Barón V, Hernández O, Oliveros G. Perforación aorto-esofágica, diagnóstico clínico e imagenológico: reporte de dos casos clínicos con manejo endovascular. Rev Colomb Cir. 2019;34:190-8. https:// doi.org/10.30944/20117582.114

12. Low Kapalu C, Lantos J, Booser A, Thomson M, Attard T. Preventing Self-Harm From Repeat Foreign-Body Ingestion. Pediatrics. 2020;145(1):e20191515. https:// doi.org/10.1542/peds.2019-1515

13. Palmer J, Osario C, Madriñán J, Montalvo A, Dr. Uro H. Extracción broncoscópica de cuerpos extraños en la vía aérea. Diez años de experiencia. Acta Pediatr Mex. 2010;31(3):102-107. https://doi.org/10.18233/ APM31No3pp 102-107

14. Doniz M, Illodo G, Pereira D, Padín L, López J, Bujanda A, Diz JC. Obstrucción glótica por cuerpo extraño en un niño. Rev Chil Anest. 2010;39(4):311-4.
15. Lee JH, Kim HC, Yang DM, Kim SW, Jin W, Park SJ, Kim $\mathrm{HJ}$. What is the role of plain radiography in patients with foreign bodies in the gastrointestinal tract? Clin Imaging. 2012;36(5):447-54. https://doi.org/10.1016/j.clinimag.2011.11.017

16. Maluenda, C, Varea, V, Bodas A. Ingesta de cuerpos extraños. En: Protocolos diagnóstico-terapéuticos de Gastroenterología, Hepatología y Nutrición Pediátrica. Madrid: Ergon; 2010. p. 131-4.

17. Fernández Landaluce A. Triaje de urgencias de pediatría. En: Protocolos diagnósticos y terapéuticos de Medicina Pediátrica de Urgencias. 3. ${ }^{\mathrm{a}}$ edición. Sociedad Española de Urgencias de Pediatría (SEUP); 2019. p. 1-14.

18. ASGE Standards of Practice Committee, Ikenberry SO, Jue TL, Anderson MA, Appalaneni V, Banerjee S, BenMenachem T, Decker GA, Fanelli RD, Fisher LR, Fukami N, Harrison ME, Jain R, Khan KM, Krinsky ML, Maple JT, Sharaf R, Strohmeyer L, Dominitz JA. Management of ingested foreign bodies and food impactions. Gastrointest Endosc. 2011;73(6):1085-91. https://doi.org/10.1016/j. gie.2010.11.010 